\title{
HUBUNGAN GAYA KEPEMIMPINAN KONTAK TANI TERHADAP PERSEPSI KINERJA KELOMPOK TANI IKAN LELE DI DESA BABAKAN, CISEENG, KABUPATEN BOGOR
}

\author{
Muhammad Rizqi Mubarok ${ }^{1)}$, dan Wahyu Budi Priatna ${ }^{2)}$ \\ ${ }^{1)}$ Program Magister Sains Agribisnis, Fakultas Ekonomi dan Manajemen, \\ Institut Pertanian Bogor \\ ${ }^{2}$ Departemen Agribisnis, Fakultas Ekonomi dan Manajemen, Institut Pertanian Bogor \\ ${ }^{1)}$ sayarizqi@gmail.com
}

\begin{abstract}
The role of Kontak tani in the group is one thing that can 't be separated to the survival of the group. Leadership styles that's applied by Kontak tani are the ways of working in order to achieve the purpose directing members of a group that can be seen from the performance. This study aims to determine the leadership styles that's generally applied by Kontak tani and the relationship of leadership styles with performance. The author use validity test, reliability test and Spearman rank test as the analysis tools in this research. Based on the research conducted, leadership styles were commonly applied by the farmer in the village of Babakan contacts are participatory that visible from the involvement of members in the group. In addition, there is a fairly strong correlation between leadership style and performance based on the perception of the group mamber. It needs a through understanding of the various stakeholders within the group or institutional farms that, establishment of groups is based on the increase in well-being and not merely for assistance.
\end{abstract}

Keyword(s): farmers group, Leadership farmers, Kontak tani, Performance

\begin{abstract}
ABSTRAK
Peran kontak tani dalam kelompok merupakan hal yang tidak terpisahkan terhadap keberlangsungan kelompok. Gaya kepemimpinan yang diterapkan oleh kontak tani merupakan cara yang dilakukan dalam mengarahkan anggota guna mencapai tujuan kelompok yang dapat terlihat dari kinerja. Penelitian ini bertujuan untuk mengetahui gaya kepemimpinan yang umumnya diterapkan oleh kontak tani dan melihat hubungan gaya kepemimpinan terhadap kinerja. Alat analisis yang digunakan adalah uji validitas, uji reliabilitas dan uji rank Spearman. Berdasarkan hasil penelitian dilakukan, gaya kepemimpinan yang umum diterapkan oleh kontak tani di Desa Babakan adalah partisipatif yang terlihat dari keterlibatan anggota di dalam kelompok. Selain itu, terdapat hubungan yang cukup kuat antara gaya kepemimpinan dan kinerja berdasarkan persepsi anggota kelompok. Perlu adanya pemahaman yang menyeluruh terhadap stakeholder yang ada didalam kelompok atau kelembagaan pertanian bahwa, pendirian kelompok didasarkan untuk peningkatan kesejahteraan dan bukan semata untuk memperoleh bantuan.
\end{abstract}

Kata Kunci: kelompok tani, kepemimpinan petani, kontak tani, kinerja 


\section{PENDAHULUAN}

Pembentukan kelembagaan diharapkan mampu menjadi sarana dalam pengembangan rumah tangga usaha budidaya secara bersama. Pengembangan pelaku utama adalah upaya mewujudkan pelaku yang dinamis, disiplin, tanggung jawab dan terampil dalam kerjasama mengelola kegiatan usaha dan meningkatkan skala usaha serta peningkatan usaha yang bersifat komersial. Pengembangan kemampuan pelaku utama dapat melalui kerjasama dengan pembentukan kelompok. Ketua kelompok tani dalam kelembagaan pertanian disebut sebagai kontak tani. Kontak tani bertanggung jawab terhadap kelompok baik terhadap anggota maupun terhadap dirinya. Tingginya tanggung jawab kontak tani menyebabkan perlu adanya kemampuan lebih yang dimiliki. Kemampuan yang dimaksud adalah kemampuan teknis dan non teknis selain itu (Miller, 2008) seorang pemimpin perlu memiliki kemampuan komunikasi, mengetahui apa yang dilakukan, berani mengambil resiko, dan memberikan kenyamanan kepada para anggota. Kemampuan teknis adalah kemampuan yang berhubungan pada budidaya usaha tani. Contohnya, pada pembudidayaan ikan lele adalah dengan memahami proses pembenihan, pemanenan sampai dengan pemasaran. Kemampuan non-teknis adalah kemampuan manajemen khususnya bagaimana cara kontak tani memimpin atau dapat dikatakan sebagai gaya kepemimpinan yang diterapkan.

Gaya kepemimpinan antar tiap kontak tani berbeda-beda. Sehingga kesesuaian dengan anggota kelompok menjadi penentu terciptanya lingkungan yang nyaman dalam kelompok. Ketidaksesuaian antara gaya kepemimpinan kontak tani dengan lingkungan dalam kelompok dapat dilihat keaktifan anggota dalam kelompok tani. Ketidaksesuaian antara gaya kepemimpinan kontak tani dan anggota dapat menurunkan kinerja. Gaya kepemimpinan yang diterapak seorang pemimpin diduga memiliki hubungan dalam mencapai kinerja kelompok yang memuaskan. Menurut Yunasaf (2005) dalam Baihaqi (2010) gaya kepemimpinan mempengaruhi keefektifan kerja dari para anggotanya. Keefektifan kerja adalah banyak usaha yang harus dilakukan untuk mencapai hasil yang optimal, sehingga keefektifan kerja yang tinggi dapat diduga karena adanya kinerja kelompok yang baik.

Kinerja kelompok merupakan tolok ukur yang menyatakan perkembangnya suatu kelompok. Kristiyanti (2012), kinerja adalah gambaran mengenai tingkat pencapaian pelaksanaan suatu kegiatan/ program/ kebijakan dalam mewujudkan sasaran, tujuan, misi dan visi organisasi yang tertuang dalam strategic planning suatu organisasi. Pengukuran kinerja menurut Lohman (2003) dalam Kristiyanti (2012) merupakan suatu aktivitas penilaian pencapaian target-target tertentu yang dideviasi dari tujuan strategis organisasi.

Keberadaan serta pembentukan kelompok pertanian tak jarang merupakan titipan khususnya dalam penggunaan bantuan. Seperti halnya yang diduga terjadi di Kecamatan Ciseeng kabupaten Bogor. Kecamatan Ciseeng merupakan salah satu sentra produksi ikan lele di 
Kabupaten Bogor. Selain menjadi kecamatan yang memiliki jumlah produksi ikan lele yang besar, jumlah unit rumah tangga petani (RTP) merupakan salah satu terbanyak di Kabupaten Bogor yaitu 625 pada tahun 2013.

Desa Babakan merupakan salah satu desa yang terletak di kecamatan Ciseeng yang memiliki jumlah produksi yang besar khususnya pada sektor ikan lele pembenihan. Desa Babakan memiliki hamparan lahan basah seluas $167000 \mathrm{Ha}$ yang secara umum digunakan sebagai pembudidayaan ikan lele 1048 jiwa penduduk di desa Babakan memilliki profesi sebagai petani dan sebagian besar menjadi petani pembudidaya ikan lele.

Jumlah petani di desa babakan yang cukup besar tidak sejalan dengan jumlah kelompok pembudidaya aktif yang ada di desa Babakan. Tercatat, menurut BP3K Kecamatan Ciseeng, hanya tesisa delapan kelompok yang masih terdaftar dari keseluruhan jumlah petani pembudidaya yang ada di Desa Babakan. Masih banyaknya petani yang tidak bergabung didalam kelompok masih dikarenakan petani tidak merasakan adanya manfaat yang jelas untuk bergabung di dalam kelompok. Pendirian kelompok berdasarkan inisiasi dari ketua yang pada umumnya hanya mengharapkan bantuan yang diberikan pemerintah melalui instansi terkait. Landasan pembentukan kelompok yang di-visi-kan oleh ketua kelompok sering disalahgunakan dan dijadikan sebagai ajakan kepada para anggota untuk bergabung kedalam kelompok. Peran pemimpin dalam mencapai tujuan bersama menjadi hal yang penting sebagai keberlangsungan kelompok dan pencapaian kinerja kelompok yang baik.

Pengamatan dilakukan untuk melihat hubungan antara gaya kepemimpinan yang diterapkan terhadap kinerja kelompok tani pembudidaya pembenihan ikan lele di Desa Babakan. Oleh karena itu perlu diteliti hubungan gaya kepemimpinan kontak tani terhadap persepsi kinerja di Desa Babakan.

Selanjutnya, peneliti merumuskan sejumlah pernyataan penelitian sebagai berikut:

1. Bagaimana gaya kepemimpinan yang diterapkan oleh ketua kontak tani terhadap kelompok tani?

2. Bagaimana hubungan dari gaya kepemimpinan yang diterapkan oleh kontak tani terhadap kinerja kelompok tani lele di Desa Babakan, Kecamatan Ciseeng, Kabupaten Bogor?

\section{METODE PENELITIAN}

\section{Lokasi dan Tempat}

Waktu penelitian adalah selama satu bulan yaitu pada minggu kedua bulan Maret sampai dengan minggu kedua bulan April 2015. Tempat penelitian adalah Desa Babakan yang terletak di Kecamatan Ciseeng Kabupaten Bogor.

\section{Jenis Data dan Sumber Data}

Jenis data yang digunakan dalam penelitian ini adalah data primer dan sekunder. Data primer diperoleh melalui wawancara kepada pihak terkait, penyebaran kuisioner, serta data dari pusat statistik daerah maupun nasional. Data sekunder yang digunakan adalah data mengenai ikan lele serta profil Desa Babakan. Selama penelitian berdasarkan 
informasi kelompok tani di Desa Babakan, peneliti hanya menemukan 4 kelompok yang masih aktif. Oleh sebab itu, dalam penelitian ini jumlah reponden yang digunakan berjumlah 40 orang. Penelitian ini tidak menggunakan sampel melaikan survey kepada seluruh responden.

Data diperoleh melalui kuisioner yang diberikan kepada responden yaitu anggota kelompok tani. Sampel ditunjuk dengan sengaja karena dianggap memahami permasalahan penelitian. Responden yang diambil dari tiap kelompok tani telah mewakili seluruh anggota yang ada dalam kelompok tani.

\section{Metode Pengumpulan Data}

Metode yang digunakan dalam mengumpulkan data adalah melalui wawancara secara terstruktur, tidak terstruktur dan dokumentasi. Wawancara terstruktur menggunakan alat bantu kuisioner kepada para anggota kelompok tani. Wawancara tidak terstruktur dilakukan kepada ketua kelompok tani beserta pihak terkait. Dokumentasi dikumpulkan sebagai pendukung penelitian.

\section{Metode Analisis Data}

Metode analisis data yang digunakan dalam penelitian ini adalah metode kualitatif dan kuantitatif. Metode kualitatif digunakan untuk mendeskripsikan komdisi kelompok dan gaya kepemimpinan kelompok yang diterapkan. Metode kuantitatif digunakan untuk melihat gaya kepemimpinan dan hubungan gaya kepemimpinan terhadap persepsi kinerja kelompok. Alat analisis yang digunakan adalah uji rank Spearman. Hal ini serupa dengan penelitian-penelitian sebelumnya yang menggunakan rank Spearman (Huda, 2012; Kosawara, 2011). Menurut Nazir (2005), koefisien korelasi ini (rank Spearman) mengukur keeratan hubungan antara dua jenis variabel dengan syarat minimal variabel ordinal, dimana dilakukan observasi.

Adapun berdasarkan uji validitas yang telah dilakukan di peroleh bahwa pada variabel gaya kepemimpinan terdapat dua indikator yang tidak valid (lampiran 3). Kedua indikator tersebut adalah jangka waktu pemberian tugas $(0.260<0.2636)$ pada gaya direktif dan pengawasan $(0.247<0.2636)$ pada gaya pengasuh. Terdapat satu indikator pada Variabel kinerja kelompok tani yang dinyatakan tidak valid (lampiran 3) yaitu perencanaan $(0.072<0.263)$. Uji reliabilitas (lampiran 4) diperoleh dapat dikatakan bahwa keseluruhan viaribel reliabel. Namun, terdapat satu variabel yang dapat dikatakan memiliki reliabilitas yang underestimate. Variabel tersebut adalah kinerja dengan nilai Cronbach's alpha sebesar 0.316 . Variabel gaya kepemimpinan memiliki nilai Cronbach's alpha sebesar 0.735.

Sedangkan pada pengujian terhadap hubungan menggunakan rank Spearman diperoleh bahwa terdapat hubungan yang cukup kuat antara gaya kepemimpinan terhadap kinerja yaitu sebesar (rs=0.495).

\section{HASIL DAN PEMBAHASAN Analisis Gaya Kepemimpinan yang Umumnya Diterapkan}

Gaya kepemimpinan yang diterapkan pada kelompok tani sangkurian indah 
adalah gaya kepemimpinan pengasuh. Hal tersebut telihat pada persentase penilaian anggota terhadap gaya kepemimpinan ketua kelompok sebesar 21.69 persen. Penilaian terhadap gaya kepemimpinan yang diterapkan oleh ketua kelompok taninya adalah gaya kepemimpinan pengasuh.

Hal tersebut terlihat dari hasil wawancara yang telah dilakukan oleh peneliti terhadap para anggota kelompok Sangkuriang Indah. Secara umum anggota mengatakan bahwa tidak adanya campur tangan dari kontak tani terhadap pekerjaan yang dilakukan. Tugas kontak tani hanya sebatas pada melakukan pengawasan dan memberikan arahan terhadap permasalahan yang dihadapi.

Tabel 1. Gaya Kepemimpinan Kelompok Sangkuriang Indah Sangkuriang Indah

\begin{tabular}{lcl}
\hline \multicolumn{1}{c}{ Gaya } & & \\
Kepemimpinan & Skor & Persentase \\
\hline Direktif & 173.00 & 17.76 \\
Supportif & 195.00 & 20.02 \\
Partisipatif & 191.00 & 19.61 \\
Orientasi Prestasi & 203.75 & 20.92 \\
Pengasuh & 211.25 & $21.69^{\text {a }}$ \\
\hline $\begin{array}{l}\text { Keterangan: }{ }^{\text {a }} \text { Presentase berdasarkan penilaian anggota } \\
\text { kelompok }\end{array}$ & \\
\end{tabular}

Gaya kepemimpinan yang diterapkan oleh kelompok tani Jumbo Lestari adalah gaya kepemimpinan Partisispatif dengan melihat hasil tabel dibawah. Hasil tersebut menunjukan bahwa sebesar 21.02 persen anggota kelompok memberikan penilaian terhadap gaya kepemimpinan partisipatif. Sebesar 20.95 persen anggota menilai gaya kepemimpinan yang diterapkan adalah direktif. Penilaian terendah anggota menganggap bahwa gaya kepemimpinan yang diterapkan adalah gaya pengasuh.

Alasan yang melatar belakangi penilaian anggota terahadap gaya kepemimpinan partisipatif adalah terlihat dalam pengambilan keputusan yang dilakukan saat rapat kelompok. Anggota menilai bahwa kepemimpinan yang dilakukan oleh Pak Mad Iwan memberikan kesempatan kepada para anggotanya dalam menyampaikan aspirasi khususnya saat rapat. Selain itu anggota menilai bahwa adanya proses yang penyampaian saran dan masukan dapat diterima dengan baik oleh kontak tani.

Tabel 2. Gaya Kepempimpinan Kelompok Jumbo Lestari

\begin{tabular}{|c|c|c|}
\hline \multicolumn{3}{|c|}{ Jumbo Lestari } \\
\hline $\begin{array}{c}\text { Gaya } \\
\text { Kepemimpinan }\end{array}$ & Skor & Persentase \\
\hline Direktif & 308 & 20.95 \\
\hline Supportif & 303 & 20.61 \\
\hline Partisipatif & 309 & $21.02^{\text {a }}$ \\
\hline Orientasi Prestasi & 280 & 19.05 \\
\hline Pengasuh & 270 & 18.37 \\
\hline
\end{tabular}

Gaya kepemimpinan yang diterapkan oleh kontak tani Mina Baraya adalah gaya kepemimpinan partisipatif. Melihat hasil pada tabel 10 , terlihat bahwa gaya kepemimpinan yang diterapkan oleh kelompok Mina Baraya adalah gaya partisipatif dengan persentase sebesar 21.35 persen. Penilaian terhadap gaya kepemimpinan lain seperti gaya kepemimpinan pangasuh sebesar 19.17 persen.

Hal tersebut dikarenakan, kontak tani masih mengikutsertakan anggotanya baik dalam pengambilan keputusan 
ataupun dalam perencanaan pembuatan tujuan kelompok. Seperti halnya dalam rapat pembuatan proposal permohonan bantuan, Pak Romli mengadakan rapat untuk menentukan jenis bantuan apa yang dibutuhkan dan diharapkan oleh para anggotanya. Baik dalam bentuk pakan, indukan, ataupun bantuan fasilitas pendukung seperti kolam.

\begin{tabular}{c} 
Tabel 3. Gaya Kepemimpinan Kelom- \\
pok Mina Baraya \\
\hline Mina Baraya
\end{tabular}

\begin{tabular}{lrl}
\hline \multicolumn{1}{c}{ Gaya } & & \\
Kepemimpinan & Skor & Persentasi \\
\hline Direktif & 166.00 & $19.58 \%$ \\
Supportif & 167.00 & $19.70 \%$ \\
Partisipatif & 181.00 & $21.35 \%^{\text {a }}$ \\
Orientasi Prestasi & 171.25 & $20.20 \%$ \\
Pengasuh & 162.50 & $19.17 \%$ \\
\hline $\begin{array}{l}\text { Keterangan: }{ }^{a} \text { Presentase berdasarkan penilaian anggota } \\
\text { kelompok }\end{array}$
\end{tabular}

Gaya kepemimpinan yang diterapkan oleh kelompok Jumbo Mandiri adalah gaya kepemimpinan partisipatif. Hal tersebut terlihat dari tabel hasil penilaian anggota mengenai gaya kepemimpinan yang diterapkan dan dirasakan oleh para anggota. Persentase penilaian gaya kepemimpinan partisipatif sebesar 22.27 persen. Penilaian terhadap gaya kepemimpinan lainnya seperti gaya kepemimpinan pengasuh memiliki persentase penilaian sebesar 17.03 persen.

Hal tersebut dikarenakan, anggota merasakan kontak tani mengajak para anggotanya dalam mengambil keputusan. Meskipun intensitas rapat yang ada dalam kelompok Jumbo Mandiri masih dapat dikatakan jarang yaitu 1 kali satu bulan atau 2 bulan 1 kali namun, dalam pengambilan keputusannya ketua tidak pernah mengambil keputusan secara sepihak tanpa melakukan proses musyawarah.

Tabel 4. Gaya Kepemimpinan Kelompok Jumbo Mandiri

\begin{tabular}{lcl}
\hline \multicolumn{3}{c}{ Jumbo Mandiri } \\
\hline $\begin{array}{c}\text { Gaya } \\
\text { Kepemimpinan }\end{array}$ & Skor & Persentasi \\
\hline Direktif & 196.00 & $19.93 \%$ \\
Supportif & 186.00 & $18.91 \%$ \\
Partisipatif & 219.00 & $22.27 \%{ }^{\text {a }}$ \\
Orientasi Prestasi & 215.00 & $21.86 \%$ \\
Pengasuh & 167.50 & $17.03 \%$ \\
\hline Keterangan: ${ }^{\text {a }}$ Presentase berdasarkan penilaian anggota
\end{tabular}
kelompok

Secara keseluruhan penilaian terhadap gaya kepemimpinan kelompok tani yang dinilai oleh seluruh anggota kelompok, menunjukan bahwa gaya kepemimpinan yang diterapkan adalah gaya kepemimpinan partsipatif. Hal tersebut dikarenakan, masih kuatnya budaya musyawarah di Desa Babakan, terlihat dari hampir seluruh kelompok tani memiliki balai atau pendopo yang digunakan sebagai tempat untuk berkumpul dan rapat. Selain itu, masih adanya kegiatan berkumpul bersama di setiap kelompok sehingga menimbulkan terjadinya komunikasi dan pertukaran pikiran dalam kelompok. Alasan lain masih kentalnya budaya menghargai di Desa Babakan mengakibatkan peran kontak tani sebagai pendengar masukan dan menerima saran yang diberikan oleh para anggotanya. 
Tabel 5. Gaya Kepemimpinan yang Dominan Digunakan Kelompok Tani Ikan Lele Di Desa Babakan Kecamatan Ciseeng

\begin{tabular}{lcc}
\hline $\begin{array}{c}\text { Gaya } \\
\text { Kepemimpinan }\end{array}$ & $\begin{array}{c}\text { Bobot } \\
\text { Penilaian }\end{array}$ & $\begin{array}{c}\text { Persentase } \\
\text { Gaya } \\
\text { Kepemimpinan }\end{array}$ \\
\hline Direktif & 843 & 19.72 \\
Supportif & 851 & 19.91 \\
Partisipatif & 900 & $21.05^{\mathrm{a}}$ \\
Orientasi Prestasi & 870 & 20.35 \\
Pengasuh & 811 & 18.98 \\
\hline Keterangan: ${ }^{\text {a }}$ Presentase berdasarkan penilaian anggota \\
\multicolumn{2}{c}{ kelompok secara keseluruhan }
\end{tabular}

Berdasarkan hasil penelitian yang diperoleh, gaya kepemimpinan yang umumnya diterapkan di sajikan pada tabel diatas. Adapun hasil dari penilaian anggota kelompok sebagai berikut :

1. Sebesar 21.05 persen dari keseluruhan anggota kelompok yang menjadi responden di Desa Babakan menyatakan bahwa, gaya kepemimpinan yang diterapkan adalah partisipatif.

2. Sebesar 20.35 persen dari seluruh responden memberikan penilaian bahwa gaya kepemimpinan yang diterapkan oleh kontak tani di Desa Babakan adalah orientasi prestasi.

3. Sebesar 19.91 persen dari seluruhan penilaian responden terhadap gaya kepemimpinan yang diterapkan oleh kontak tani di Desa Babakan adalah supportif.

4. Sebesar 19.72 persen dari keseluruhan penilaian responden terhadap gaya kepemimpinan yang diterapkan oleh kontak tani di Desa Babakan adalah direktif.

5. Sebesar 18.98 persen dari keseluruhan penilaian responden terhadap gaya kepemimpinan yang diterapkan oleh kontak tani di Desa Babakan adalah pengasuh.

\section{Hubungan Gaya Kepemimpinan ter- hadap Kinerja}

Berdasarkan data yang diperoleh selama penelitian, untuk mengetahui adanya hubungan antara gaya kepemimpinan dan kinerja perlu dilakukan pengujian menggunakan rank spearman. Adapun hasil uji rank spearman antara gaya kepemimpinan dan kinerja di kelompok tani ikan lele di Desa Babakan sebesar $(\mathrm{rs}=0.49)$ pada $\alpha=0.001$.

Berdasarkan hasil uji rank spearman, diketahui bahwa terdapat hubungan yang nyata antara gaya kepemimpinan dan kinerja. Adapun keeratan hubungannya (rs=0.49) dapat dikatakan memiliki hubungan yang cukup berarti dan bersifat positif. Sehingga dapat dikatakan peningkatan kinerja di kelompok dapat melalui gaya kepemimpinan yang diterapkan oleh kontak tani. Kinerja di kelompok yang dapat ditingkatkan dapat berupa kinerja kelompok, kontak tani dan anggota. Peningkatan kinerja kelompok tersebut dapat melalui penerapan gaya kepemimpinan direktif, supportif, partisipatif, orientasi, dan pengasuh. Salah satu gaya kepemimpinan yang tidak secara keseluruhan berhubungan secara nyata terhadap kinerja adalah gaya kepemimpinan suportif. Setiap gaya kepemimpinan yang digunakan dalam penelitian dapat berhubungan nyata ataupun tidak berhubungan nyata sama sekali terhadap kinerja. 


\section{SIMPULAN DAN SARAN}

\section{Simpulan}

1. Gaya kepemimpinan yang diterapkan oleh masing-masing ketua kelompok tani adalah gaya kepemimpinan pengasuh diterapkan pada kelompok Sangkuriang Indah. Kontak tani Jumbo Mandiri, Mina Baraya, dan Jumbo Lestari menerapkan gaya kepemimpinan partisipatif.

2. Gaya kepemimpinan yang umumnya digunakan oleh kelompok tani di Desa Babakan adalah gaya kepemimpinan partisipatif. Hal tersebut terlihat dari persentase penilaian yang diberikan oleh seluruh responden dari tiap kelompok tani.

3. Terdapat hubungan nyata yang cukup berarti antara gaya kepemimpinan dan kinerja pada kelompok tani ikan lele di Desa Babakan Kecamatan Ciseeng. Terdapat hubungan nyata cukup berarti antara gaya kepemimpinan direktif dan kinerja kelompok serta kenerja kontak tani. Gaya kepemimpinan partisipatif memiliki hubungan nyata yang cukup berarti dengan kinerja kelompok dan hubungan yang rendah tapi pasti dengan kinerja kontak tani. Gaya kepemimpinan orientasi prestasi dan pengasuh, memiliki hubungan nyata yang cukup berarti terhadap kinerja anggota. Gaya kepemimpinan supportif dalam penelitian ini tidak memiliki hubungan nyata terhadap kinerja kelompok, kontak tani maupun anggota.

\section{Saran}

Perlu diperhatikan kinerja kelompok dan para anggotanya oleh kontak tani. Selain itu, adanya rapat dalam kelompok dibutuhkan agar pemimpin dapat menyalurkan kemampuan yang dimiliki kepada seluruh anggota. Perlu adanya pembuatan agenda dalam kelompok yang dijalankan bersama sehingga antar anggota dalam kelompok tidak hanya berjalan atau bekerja secara sendiri. Perlu adanya pemahaman terhadap pendirian kelompok tani yang tidak hanya berlandaskan pada adanya bantuan, melainkan pada peningkatan kesejahteraan secara bersama. Oleh sebab itu diperlukan kemampuan kontak tani untuk mengarahkan para anggota dalam kelompoknya.

\section{DAFTAR PUSTAKA}

Baihaqi, Muhammad Fauzan. 2010. Pengaruh Gaya Kepemimpinan Terhadap Kepuasan Kerja Dan Kinerja Dengan Komitmen Organisasi Sebagai Variabel Intervening.[skripsi].Semarang

(ID):

Fakultas Ekonomi.Universitas Dipenogoro.

[Disnakan] Dinas Peternakan dan Perikanan Kabupaten Bogor. 2011. Buku Data Perkanan. Bogor (ID): Disnakan.

[Disnakan] Dinas Peternakan dan Perikanan Kabupaten Bogor. 2012. Buku Data Perkanan. Bogor (ID): Disnakan.

[Disnakan] Dinas Peternakan dan Perikanan Kabupaten Bogor. 2013. Buku Data Perkanan. Bogor (ID): Disnakan. 
Huda A. 2012. Korelasi Kinerja Pegawai, Gaya Kepemimpinan dan Lingkungan Kerja. Jawa Tengah (ID): Badan Pendidikan dan Pelatihan Provinsi Jawa Tengah.

[KKP] Kementrian Kelautan dan Perikanan. 2012. Keputusan Menteri Kelautan dan Perikanan Republik Indonesia Nomor 14 Tahun 2012 tentang Pedoman Umum Penumbuhan dan Pengembangan Kelembagaan Pelaku Utama Perikanan. (ID): KKP.

Koswara, Denny. 2011. Partisipasi Anggota dan Kinerja Gabungan Kelompok Tani Agroprna Mitra Mandiri di Kabupaten Bandung Barat Provinsi Jawa Barat. [skripsi]. Bogor (ID): Fakultas Ekonomi dan Manajemen. Institut Pertanian Bogor.

Kristiyanti M. 2012. Peran Indikator Kinerja dalam Mengukur Kinerja Manajemen [Jurnal]. (ID): Majalah Ilmiah Informatika. 3(3):103-123. September 2012.

Miller BS, 2008. Developing Leadership on Boards of Directors. [Jurnal]. (NY): Journal for nonprofit management. Vol 12, No.1.

Nazir M. 2005. Metode Penelitian. Bogor (ID): Ghalia Indonesia.

Sitanggang C, 2005, Analisis Pengaruh Perilaku Pemimpin Terhadap Kinerja Pegawai Pada Sekretariat Kotamadya Jakarta Barat. [Skripsi]. Semarang (ID): Universitas Diponogoro.
Yulk GA. 2005. Kepemimpinan dalam Organisasi. Edisi Kelima. Budi S, penerjemah; Eli T, editor. Jakarta (ID): Penerbit PT Indeks Kelompok Gramedia. Terjemah dari: Leadership in Organization.

Yunasaf U. 2005. Kepemimpinan Ketua Kelompok dan Hubungannya dengan Keefektifan Kelompok. [Skripsi]. Bandung (ID): Fakultas Peternakan.Universitas Padjajaran. 
Lampiran 1. Hasil Rank Spearman Gaya Kepemimpinan dengan Kinerja

\begin{tabular}{|c|c|c|c|c|c|c|}
\hline \multicolumn{7}{|c|}{ Correlations } \\
\hline & & & & & gaya & kinerja \\
\hline \multirow{14}{*}{$\begin{array}{l}\text { Spearman's } \\
\text { rho }\end{array}$} & \multirow[t]{7}{*}{ gaya } & \multicolumn{3}{|c|}{ Correlation Coefficient } & 1.000 & $.495^{* *}$ \\
\hline & & \multicolumn{3}{|c|}{ Sig. (2-tailed) } & & .001 \\
\hline & & \multicolumn{3}{|l|}{$\mathrm{N}$} & 40 & 40 \\
\hline & & \multirow[t]{4}{*}{ Bootstrap $^{c}$} & \multicolumn{2}{|l|}{ Bias } & 0.000 & .003 \\
\hline & & & \multicolumn{2}{|l|}{ Std. Error } & 0.000 & .137 \\
\hline & & & \multirow{2}{*}{$\begin{array}{l}\text { 95\% Confidence } \\
\text { Interval }\end{array}$} & Lower & 1.000 & .244 \\
\hline & & & & Upper & 1.000 & .760 \\
\hline & \multirow[t]{7}{*}{ kinerja } & \multicolumn{3}{|c|}{ Correlation Coefficient } & $.495^{* *}$ & 1.000 \\
\hline & & \multicolumn{3}{|c|}{ Sig. (2-tailed) } & .001 & \\
\hline & & \multicolumn{3}{|l|}{$\mathrm{N}$} & 40 & 40 \\
\hline & & \multirow[t]{4}{*}{ Bootstrap $^{c}$} & \multicolumn{2}{|l|}{ Bias } & .003 & 0.000 \\
\hline & & & \multicolumn{2}{|l|}{ Std. Error } & .137 & 0.000 \\
\hline & & & \multirow{2}{*}{$\begin{array}{l}\text { 95\% Confidence } \\
\text { Interval }\end{array}$} & Lower & .244 & 1.000 \\
\hline & & & & Upper & .760 & 1.000 \\
\hline \multicolumn{7}{|c|}{ **. Correlation is significant at the 0.01 level (2-tailed). } \\
\hline \multicolumn{7}{|c|}{ *. Correlation is significant at the 0.05 level (2-tailed). } \\
\hline \multicolumn{7}{|c|}{ c. Unless otherwise noted, bootstrap results are based on 40 bootstrap samples } \\
\hline
\end{tabular}

\section{Lampiran 2. Hasil Validitas Variabel Kinerja}

\begin{tabular}{llc}
\hline Variabel & Indikator & Keterangan \\
\hline Kinerja & & \\
Kelompok tani & Perencanaan & Tidak valid \\
& Tepat_waktu & Valid \\
& Keuangan & Valid \\
& Komunikasi & Valid \\
& Pelatihan & Valid \\
Kontak tani & Peningkatan_prestasi & Valid \\
& Pengaruh & Valid \\
& Rasa_puas & Valid \\
& Tanggung_jawab & Valid \\
& Peningkatan_produksi & Valid \\
& Tujuan_kelompok & Valid \\
& Visi & Valid \\
Anggota kelompok & Penyelesaian_tugas & Valid \\
& Satu_waktu & Valid \\
& Hadir_rapat & Valid \\
& Inisiatif & Valid \\
& Lebih_baik & Valid \\
\hline
\end{tabular}


Lampiran 3. Hasil Validitas Variabel Gaya Kepemimpinan

\begin{tabular}{clc}
\hline Variabel & Indikator & Keterangan \\
gaya kepemimpinan & & \\
& perencanaan & valid \\
arahan & valid \\
& jandar_kerja & valid \\
& koordinasi & tidak valid \\
aturan & valid \\
supportif & ramah & valid \\
& dukungan_moril & valid \\
& pengamatan_anggota & valid \\
& mudah_ditemui & valid \\
& tekanan & valid \\
rapat_isipatif & pengambilan_keputusan & valid \\
& menerima_saran & valid \\
& mendengarkan_masukan & valid \\
& musyawarah & valid \\
& pengharapan & valid \\
& potensi & valid \\
orientasi prestasi & standar_tinggi & valid \\
& tujuan_kegiatan & valid \\
& kebebasan & valid \\
& ikut_campur & valid \\
& bekerja_baik & valid \\
& pengawasan & valid \\
& penyelesaian_tugas & valid \\
& & tidak valid \\
& & valid \\
\hline & &
\end{tabular}

Lampiran 4. Hasil Uji Reliabilitas

\begin{tabular}{lrrr}
\multicolumn{1}{c}{ Keterangan } & $\begin{array}{c}\text { Cronbach's } \\
\text { Alpha }\end{array}$ & $\begin{array}{c}\text { Cronbach's Alpha } \\
\text { Based on Standardized } \\
\text { Items }\end{array}$ & N of Items \\
\hline $\begin{array}{l}\text { Gaya Kepemimpinan } \\
\text { Kinerja }\end{array}$ & .735 & .747 & 23 \\
$\quad$ Kelompok & .876 & .880 & 5 \\
Kontak Tani & .316 & .292 & 6 \\
Anggota & .619 & .628 & 5 \\
\hline
\end{tabular}


Lampiran 5 Hubungan Gaya Kepemimpinan dengan Kinerja

\begin{tabular}{lccccc}
\hline \multirow{2}{*}{ Kinerja } & \multicolumn{5}{c}{ Gaya Kepemimpinan } \\
\cline { 2 - 6 } & Direktif & Supportif & Partisipatif & Orientasi Prestasi & Pengasuh \\
\hline Kelompok & $0.48^{\mathrm{a}}$ & 0.29 & $0.45^{\mathrm{a}}$ & -0.08 & -0.29 \\
Kontak Tani & $0.45^{\mathrm{a}}$ & 0.16 & $0.39^{\mathrm{a}}$ & 0.27 & -0.23 \\
Anggota & -0.20 & 0.15 & -0.24 & $0.47^{\mathrm{a}}$ & $0.48^{\mathrm{a}}$ \\
\hline
\end{tabular}

